\title{
Assessment of body weight, maternal dietary knowledge and lifestyle practices among children and adolescents in north Jordan
}

\author{
Hadil S Subih ${ }^{1, *}$, Yaqeen Abu-Shquier ${ }^{1}$, Hiba Bawadi ${ }^{1}$ and Nahla Al-Bayyari ${ }^{2}$ \\ 'Department of Nutrition and Food Technology, Faculty of Agriculture, Jordan University of Science and Technology, \\ PO Box 3030, Irbid 22110, Jordan: ${ }^{2}$ Department of Nutrition and Food Technology, Al-Huson University College, \\ Al-Balqa Applied University, Al-Salt, Jordan
}

Submitted 3 January 2018: Final revision received 26 April 2018: Accepted 8 May 2018: First published online 11 June 2018

\begin{abstract}
Objective: To estimate the prevalence of overweight and obesity among children and adolescents in north Jordan and to evaluate the dietary knowledge of their mothers.

Design: Cross-sectional study.

Settings: Schools, Irbid, Jordan.

Subjects: Male and female participants ( $n$ 516) aged 6-18 years.

Results: Thirty per cent of our sample population was overweight or obese, and about $11 \%$ was underweight. Males tend to have a higher BMI and waist circumference than females except in the age group $\geq 15$ years. Children who ate in front of the television tended to have higher BMI and waist circumference. Forty per cent of the mothers answered four or more questions correctly out of six, which indicated a sufficient level of nutritional knowledge.

Conclusions: The study revealed that obesity is a growing health problem in children and adolescents in north Jordan. This finding is considered a serious concern for public health and calls for the creation of new prevention programmes at the individual, family and community level.
\end{abstract}

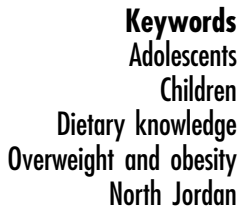

Obesity is the accumulation of body fat which has a negative effect on person's health. A person is considered obese if his/her body weight is $20 \%$ higher than normal ${ }^{(1)}$. Growth charts have been constructed by observing the growth of large numbers of normal children over time ${ }^{(2)}$. The height, weight and head circumference of a child can be compared with the expected parameters of children of the same age and sex to determine whether the child is growing appropriately ${ }^{(3)}$.

Childhood overweight and obesity is a health problem that needs effective approaches. Its prevalence is becoming a threat to public health worldwide, affecting both developed and developing nations. Overweight and obesity represent a rapidly growing risk to the health of people in an increasing number of countries ${ }^{(4)}$. For many developing countries, obesity and its consequences have become a challenge like hunger and undernutrition ${ }^{(5)}$.

Recently, there has been an increase in prevalence of childhood obesity (5-19 years) due to rapid change in dietary practices and adoption of sedentary lifestyles in developing countries ${ }^{(6)}$. Prevalence of childhood overweight and obesity worldwide has increased from $4.2 \%$ in 1990 to $6.7 \%$ in $2010^{(7)}$. The trend is anticipated to reach
$9.1 \%$ in 2020. The estimated prevalence of childhood overweight and obesity in Africa in 2010 was $8.5 \%$ and is expected to reach $12.7 \%$ in $2020^{(7)}$.

Overweight and obesity in children and adolescents is progressively being observed alongside improved access to technology that is associated with varying lifestyle of families due to increased purchasing power, luxurious living, increasing hours of inactivity due to increased watching of television (TV) and use of video games and computers, which seem to substitute for outdoor games and other social activities ${ }^{(8,9)}$. The trend of overweight and obesity is rising with urbanization, changes in lifestyle and social economic transition. Social economic transition is considered to be among the causes of overweight and obesity, in which residing in cities provides greater access to more fast foods and the emergence of people with high economic income who can afford these fast foods with high glycaemic index ${ }^{(10,11)}$. Children's physical and psychological health is highly affected by overweight and obesity. The mechanism of overweight and obesity is not well understood but is believed to be disorder of multiple causes. It is assumed to be a result of increasing intakes of energy and fat. According to experimental and observational 
studies, both diet and physical activity have a positive effect on decreasing obesity and controlling body weight ${ }^{(3)}$.

Obesity and/or overweight are major risk factors for chronic diseases and play a central role in insulin resistance as well as the metabolic syndrome, which includes hyperinsulinaemia, hypertension, hyperlipidaemia and type 2 diabetes mellitus ${ }^{(12)}$. Obesity also correlates strongly with increased risk of atherosclerotic CVD, stroke, sleep apnoea syndrome and some forms of cancer ${ }^{(12-15)}$. However, little is known about the prevalence of childhood obesity and the paediatric metabolic syndrome in developing countries because of the limited number of studies, the variety of definitions and cut-offs used and the different age groups studied, which makes comparisons difficult ${ }^{(12)}$. Among developing countries, the prevalence of childhood obesity is highest in the Middle East and Central and Eastern Europe ${ }^{(16)}$. Due to a lack of statistics for overweight/obesity among schoolchildren in Jordan, the present study was conducted to assess the prevalence of overweight and obesity in Jordanian children and adolescents and to investigate the level of maternal nutritional knowledge and dietary information.

\section{Methods}

\section{Study approval}

Approval of the Institutional Review Boards of the Medical School of Jordan University of Science and Technology and King Abdullah University Hospital, Irbid, was obtained first before the study was initiated.

\section{Participants}

The study was of analytical cross-sectional design and conducted in autumn 2016. A convenience sample of 516 children and adolescents aged 6-18 years was recruited. The sample was selected randomly from four public and four private schools in different areas of Irbid city in the north of Jordan.

\section{Procedures}

The researcher met with school administrations to provide all details about the study and to explain its objectives. Random classes from elementary, secondary and high schools were selected to guarantee the participation of all age groups. Based on the school administration's preference, a specific time was chosen to let the researcher meet with all students and explain all the questions in the questionnaire. The researcher also mentioned the importance of the study and the privacy of the information to be collected. All participants were given a consent form and information sheet explaining the general background of the study and received a brief verbal explanation regarding the research objectives. All participants had the right to drop out during the study period.

\section{Measures}

\section{Questionnaire}

A trained researcher helped all students from all different age groups to fill out a pre-designed and pre-tested questionnaire; all questions were explained clearly to the students to guarantee understanding and accurate answers. The questionnaire was designed and circulated to three faculty members to review and it was modified based on their suggestions. Feedback comments were done to validate the questionnaire. The questionnaire had five sections. The first three concerned sociodemographic characteristics, general health and eating behaviours, which focused mainly on the number of meals taken daily, number of snacks, amount of water consumption and frequency of eating fast foods. The fourth section asked about lifestyle practices such as sleeping patterns, parental smoking habits, parents' weight and height, electronic devices and watching TV. The last section of the questionnaire focused on physical activity level. The parents' weight and height were recorded and then parental BMI was calculated to categorize them based on their BMI.

\section{Anthropometric assessment}

At the beginning of each class meeting, the researcher measured each student's body weight, height and waist circumference (WC). Body height was measured to the nearest $0 \cdot 1 \mathrm{~cm}$ using a stadiometer and weight was measured to the nearest $0 \cdot 1 \mathrm{~kg}$ using a standard weighing scale, with the child wearing light clothes and barefoot. WC was measured to the nearest centimetre using a nonstretchable circumference-measuring tape (SECA 203, Germany). The site of tape placement was determined according to the WHO's description of midway between the iliac crest and the lower rib border ${ }^{(4)}$. According to the WHO, there are no cut-off points for WC in children. Three measurements were recorded, and the average was taken. BMI was calculated as body weight in kilograms divided by the square of height in metres $\left(\mathrm{kg} / \mathrm{m}^{2}\right)$. Agespecific cut-off points of BMI (with the age ranging from 2 to 18 years) for the diagnosis of overweight and obesity were used. Those between the 85th percentile and 95th percentile on the growth chart were considered overweight, while underweight was set to be $\leq 5$ th percentile $^{(17,18)}$

\section{Nutritional knowledge of mothers}

To examine the nutritional knowledge of parents, especially mothers, a quiz specifically developed for this purpose was circulated to three faculty members who were professionals in this domain to guarantee the simplicity, accuracy and validity. Modifications were done to the quiz based on the reviewers' comments and suggestions. Six questions were included in the quiz. The questions focused mainly on the number of cups of water children need to consume, best fat/oil choices, which food items 
may cause obesity, healthy snack choices, the number of meals children need and foods rich in vitamins and minerals.

The students were encouraged to bring back the quiz the next day. Students were told that they would be given a prize when they brought back the quiz from their mothers/ guardians. The prize was a set comprising a pencil, eraser, sharpener and notebook. Parents who answered four or more questions correctly out of the six (more than half of the questions) were considered to have adequate dietary information, while those who answered three or fewer questions correctly were considered to have a low level of dietary knowledge. The children demonstrated that mostly their mothers had answered the quiz questions (95\%), while fathers answered the quiz in $5 \%$ of the cases only.

\section{Statistical analysis}

Collected data were entered in a data sheet and analysed using the statistical software package IBM SPSS Statistics version 19. Data were initially examined by performing descriptive statistics for all categorical and continuous variables. Characteristics of the participants were expressed as number and percentage using frequency distribution for categorical variables. Means and standard deviations were used for continuous variables after a Shapiro-Wilk test was performed to check normality. Data were normally distributed and ANOVA was used to examine the impact of age, gender, sociodemographic status, eating behaviour and lifestyle characteristics on participants' BMI and WC. $P<0.05$ was considered significant.

\section{Results}

The sociodemographic and health characteristics of the students included in the study are presented in Table 1, which shows that about two-thirds of the population were females while only one-third were males (68\% v. 32\%). Age of the students ranged from 9 to 17 years; $46 \%$ of male students were in the age group $\geq 15$ years while $40 \%$ of female students fell in that age group. Fifty-six per cent belonged to an extended family and about half of the participants had at least one working parent. Moreover, most of the students did not have any health problem except $19 \%$ of them had allergy, and $58 \%$ had healthyweight parents.

Table 2 shows that most of the study population considered lunch as the main meal (86\%). Nearly all of them (93.8\%) got fewer than three snacks per day. Eighty per cent of the participants worried about the quality of food they eat and $81 \%$ revealed that they usually eat homemade food only. Seventy-four per cent revealed they take fewer than four cups of water daily. About $57 \%$ of males and $70 \%$ of females slept more than $8 \mathrm{~h} / \mathrm{d}$.

Regarding lifestyle characteristics, the study showed that 88.6\% of the students had an electronic device at home, as shown in Table 2. Among the 516 students, 39\% of them

Table 1 Sociodemographic and health characteristics of the children and adolescents $(n 516)$ by gender, Irbid, north Jordan, autumn 2016

\begin{tabular}{|c|c|c|c|c|c|c|c|}
\hline \multirow[b]{2}{*}{ Variable } & \multicolumn{2}{|c|}{ Total } & \multicolumn{2}{|c|}{ Males } & \multicolumn{2}{|c|}{ Females } & \multirow[b]{2}{*}{$P$ value* } \\
\hline & $n$ & $\%$ & $n$ & $\%$ & $n$ & $\%$ & \\
\hline Age (years) & & & & & & & 0.000 \\
\hline$\leq 10$ & 103 & $20 \cdot 0$ & 31 & $18 \cdot 8$ & 72 & 20.5 & \\
\hline $11-14$ & 174 & $33 \cdot 7$ & 34 & $20 \cdot 6$ & 140 & 39.9 & \\
\hline$\geq 15$ & 239 & $46 \cdot 3$ & 100 & $60 \cdot 6$ & 139 & 39.6 & \\
\hline Living place & & & & & & & 0.613 \\
\hline Rural & 355 & $68 \cdot 8$ & 116 & $70 \cdot 3$ & 239 & $68 \cdot 1$ & \\
\hline Urban & 161 & $31 \cdot 2$ & 49 & $29 \cdot 7$ & 112 & 31.9 & \\
\hline No. of family members & & & & & & & 0.786 \\
\hline$\leq 6$ & 224 & 43.4 & 72 & 43.6 & 152 & 43.3 & \\
\hline $7-9$ & 233 & $45 \cdot 2$ & 72 & $43 \cdot 6$ & 161 & 45.9 & \\
\hline$\geq 10$ & 59 & 11.4 & 21 & $12 \cdot 7$ & 38 & $10 \cdot 8$ & \\
\hline No. of working family members & & & & & & & 0.064 \\
\hline 1 & 252 & $48 \cdot 8$ & 93 & $56 \cdot 4$ & 159 & $45 \cdot 3$ & \\
\hline 2 & 230 & $44 \cdot 6$ & 63 & $38 \cdot 2$ & 167 & $47 \cdot 6$ & \\
\hline$>2$ & 34 & $6 \cdot 6$ & 9 & $5 \cdot 5$ & 25 & $7 \cdot 1$ & \\
\hline Allergy & & & & & & & 0.806 \\
\hline Yes & 97 & $18 \cdot 8$ & 30 & $18 \cdot 2$ & 67 & $19 \cdot 1$ & \\
\hline No & 419 & $81 \cdot 2$ & 135 & $81 \cdot 8$ & 284 & 80.9 & \\
\hline Health problems & & & & & & & 0.545 \\
\hline Yes & 53 & $10 \cdot 3$ & 15 & $9 \cdot 1$ & 38 & $10 \cdot 8$ & \\
\hline No & 463 & $89 \cdot 7$ & 150 & $90 \cdot 9$ & 313 & $89 \cdot 2$ & \\
\hline Parents' weight & & & & & & & 0.842 \\
\hline Both normal & 474 & $58 \cdot 0$ & 154 & $93 \cdot 3$ & 320 & $91 \cdot 2$ & \\
\hline Both obese & 21 & $15 \cdot 0$ & 5 & 3.0 & 16 & $4 . \overline{6}$ & \\
\hline Normal father and obese mother & 11 & $15 \cdot 1$ & 3 & 1.8 & 8 & $2 \cdot 3$ & \\
\hline Normal mother and obese father & 10 & 11.9 & 3 & $1 \cdot 8$ & 7 & $2 \cdot 0$ & \\
\hline
\end{tabular}

*Values are significantly different between genders by the least significant difference test if $P<0.05$. 
Table 2 Lifestyle characteristics of the children and adolescents ( $n$ 516) by gender, Irbid, north Jordan, autumn 2016

\begin{tabular}{|c|c|c|c|c|c|c|c|}
\hline \multirow[b]{2}{*}{ Variable } & \multicolumn{2}{|c|}{ Total } & \multicolumn{2}{|c|}{ Males } & \multicolumn{2}{|c|}{ Females } & \multirow[b]{2}{*}{$P$ value* } \\
\hline & $n$ & $\%$ & $n$ & $\%$ & $n$ & $\%$ & \\
\hline No. of meals daily & & & & & & & 0.744 \\
\hline 1 & 17 & 3.3 & 6 & 3.6 & 11 & $3 \cdot 1$ & \\
\hline 2 & 84 & $16 \cdot 3$ & 23 & 13.9 & 61 & $17 \cdot 4$ & \\
\hline 3 & 384 & $74 \cdot 4$ & 127 & 74.4 & 257 & 73.2 & \\
\hline$>3$ & 31 & $6 \cdot 0$ & 9 & 5.5 & 22 & $6 \cdot 3$ & \\
\hline Main meal & & & & & & & $0 \cdot 158$ \\
\hline Breakfast & 48 & $9 \cdot 3$ & 11 & $6 \cdot 7$ & 37 & $10 \cdot 5$ & \\
\hline Lunch & 444 & 86.0 & 149 & $90 \cdot 3$ & 295 & 84.0 & \\
\hline Dinner & 24 & 4.7 & 5 & 3.0 & 19 & $5 \cdot 4$ & \\
\hline Worry about food quality & & & & & & & 0.274 \\
\hline Yes & 414 & $80 \cdot 2$ & 137 & 83.0 & 277 & 78.9 & \\
\hline No & 102 & $19 \cdot 8$ & 28 & $27 \cdot 0$ & 74 & 21.1 & \\
\hline Type of food & & & & & & & 0.006 \\
\hline Homemade & 418 & $81 \cdot 0$ & 127 & $77 \cdot 0$ & 291 & 82.9 & \\
\hline Restaurants & 88 & $17 \cdot 1$ & 38 & 23.0 & 50 & $14 \cdot 2$ & \\
\hline Both & 10 & 1.9 & 0 & 0.0 & 10 & $2 \cdot 8$ & \\
\hline No. of snacks daily & & & & & & & 0.489 \\
\hline$\leq 3$ & 484 & 93.8 & 153 & $92 \cdot 7$ & 331 & $94 \cdot 3$ & \\
\hline$\geq 4$ & 32 & $6 \cdot 2$ & 12 & $7 \cdot 3$ & 20 & $5 \cdot 7$ & \\
\hline No. of cups of water daily & & & & & & & 0.238 \\
\hline$<4$ & 383 & $74 \cdot 2$ & 117 & 70.9 & 266 & $75 \cdot 8$ & \\
\hline$\geq 4$ & 133 & $25 \cdot 8$ & 48 & 29.1 & 85 & 24.2 & \\
\hline Got an electronic device & & & & & & & 0.353 \\
\hline Yes & 474 & $88 \cdot 6$ & 143 & $86 \cdot 7$ & 314 & $89 \cdot 5$ & \\
\hline No & 59 & 11.4 & 22 & $13 \cdot 3$ & 37 & $10 \cdot 5$ & \\
\hline Watching TV & & & & & & & 0.033 \\
\hline Yes & 501 & $97 \cdot 1$ & 164 & 99.4 & 337 & $96 \cdot 0$ & \\
\hline No & 15 & $2 \cdot 9$ & 1 & 0.6 & 14 & 4.0 & \\
\hline Eating in front of TV & & & & & & & 0.696 \\
\hline Yes & 202 & $39 \cdot 2$ & 75 & 45.5 & 166 & $47 \cdot 3$ & \\
\hline No & 314 & $60 \cdot 8$ & 90 & 54.5 & 185 & $52 \cdot 7$ & \\
\hline Sleeping (h) & & & & & & & 0.003 \\
\hline$\leq 8$ & 176 & 43.1 & 71 & 43.0 & 104 & $29 \cdot 7$ & \\
\hline$>8$ & 340 & $65 \cdot 9$ & 94 & $57 \cdot 0$ & 246 & $70 \cdot 3$ & \\
\hline Physically active ( $\geq 60 \mathrm{~min} / \mathrm{d}$ ) & & & & & & & $0 \cdot 213$ \\
\hline Yes & 227 & $44 \cdot 0$ & 83 & $50 \cdot 3$ & 156 & $44 \cdot 4$ & \\
\hline No & 289 & $66 \cdot 0$ & 82 & 49.7 & 195 & $55 \cdot 6$ & \\
\hline
\end{tabular}

TV, television.

*Values are significantly different between genders by the least significant difference test if $P<0.05$.

were eating while watching TV. Only $44 \%$ of the participants reported that they consider themselves physically active (incorporate about $60 \mathrm{~min}$ of moderate exercising daily). Nearly $30 \%$ of the study sample was overweight/ obese (overall prevalence among the study group $=29.5 \%$ ) and thus obesity seems to be a common problem among children in north Jordan. On the other hand, 59\% of the participants had normal weight and almost $11 \%$ were underweight.

Children and adolescents in the present study were divided into three groups based on their age as follows: the first group included children aged $\leq 10$ years, the second group included adolescents aged 11-14 years old and the third group included adolescents aged $\geq 15$ years. The children's and adolescents' anthropometric characteristics based on their age group showed that there was a significant increase in mean BMI, WC, height and weight in general, as shown in Table 3. This increase in BMI and WC is expected because children grow fast during this stage of their lives.
Examination of the means of BMI and WC according to gender, age, place of living and eating while watching TV showed that there was a significant difference $(P<0.05)$ by BMI and gender among all age groups (Table 4$)$. Males tended to have a higher BMI than females $(P<0.05)$ in all age groups except the $\geq 15$ years group, where females had a higher BMI mean than males (22.73 (SD 7.30) $v$. 22.57 (SD 5.56 ) kg/m², respectively; $P<0.05$ ). A similar trend was also observed concerning WC between males and females, where males had a significantly higher mean WC compared with females in the age groups $\leq 10$ years and $\geq 15$ years $(P<0.05)$. Mean BMI and WC among children and adolescents according to urban or rural residency showed that children living in urban areas had significantly a higher mean BMI than those living in rural areas in all three age groups $(P<0 \cdot 05)$. Likewise, mean WC for urban children aged $\leq 10$ years and $\geq 15$ years was significantly higher than that of their counterparts living in rural areas $(P<0.05)$. Both mean BMI and WC were significantly higher in children who ate in front of the TV 
Table 3 Anthropometric characteristics of the children and adolescents ( $n$ 516) by age group, Irbid, north Jordan, autumn 2016

\begin{tabular}{|c|c|c|c|c|c|c|c|}
\hline \multirow[b]{2}{*}{ Variable } & \multicolumn{2}{|c|}{$\leq 10$ years } & \multicolumn{2}{|c|}{$11-14$ years } & \multicolumn{2}{|c|}{$\geq 15$ years } & \multirow[b]{2}{*}{$P$ value } \\
\hline & Mean & SD & Mean & $\mathrm{SD}$ & Mean & SD & \\
\hline BMI $(\mathrm{kg} / \mathrm{m})^{2}$ & $19 \cdot 1$ & $4 \cdot 1$ & $19 \cdot 4$ & $3 \cdot 2$ & 22.7 & 4.3 & 0.000 \\
\hline WC $(\mathrm{cm})$ & 69.5 & $12 \cdot 3$ & 74.2 & $10 \cdot 8$ & 83.7 & $15 \cdot 2$ & 0.000 \\
\hline Height $(\mathrm{cm})$ & 141.5 & $10 \cdot 6$ & 149.5 & $10 \cdot 2$ & 164.2 & 9.9 & 0.000 \\
\hline Weight (kg) & 38.4 & 10.0 & 43.6 & $12 \cdot 1$ & 61.4 & $15 \cdot 6$ & 0.000 \\
\hline
\end{tabular}

WC, waist circumference.

*Values are significantly different between age groups by the least significant difference test if $P<0.05$.

Table 4 Mean BMI and waist circumference of the children and adolescents ( $n 516)$ by age, gender, place of living and eating in front of the television, Irbid, north Jordan, autumn 2016

\begin{tabular}{|c|c|c|c|c|c|c|c|}
\hline \multirow[b]{2}{*}{ Age group } & \multirow[b]{2}{*}{ Variable } & \multicolumn{3}{|c|}{ BMI $\left(\mathrm{kg} / \mathrm{m}^{2}\right)$} & \multicolumn{3}{|c|}{$W C(\mathrm{~cm})$} \\
\hline & & Mean & SD & $P$ value* & Mean & SD & $P$ value ${ }^{*}$ \\
\hline \multirow[t]{2}{*}{$\leq 10$ years } & Males & $19 \cdot 6$ & $4 \cdot 39$ & 0.032 & $76 \cdot 4$ & $11 \cdot 14$ & 0.032 \\
\hline & Females & $18 \cdot 2$ & 3.47 & & $69 \cdot 2$ & $10 \cdot 69$ & \\
\hline \multirow[t]{2}{*}{$11-14$ years } & Males & $20 \cdot 8$ & $5 \cdot 57$ & 0.036 & $88 \cdot 6$ & 11.78 & $0 \cdot 61$ \\
\hline & Females & $20 \cdot 3$ & $2 \cdot 81$ & & $79 \cdot 2$ & $7 \cdot 81$ & \\
\hline \multirow[t]{2}{*}{$\geq 15$ years } & Males & $22 \cdot 6$ & 5.56 & 0.014 & $95 \cdot 2$ & 11.44 & 0.021 \\
\hline & Females & $22 \cdot 7$ & 4.25 & & $75 \cdot 9$ & $12 \cdot 04$ & \\
\hline \multirow[t]{2}{*}{$\leq 10$ years } & Rural & $18 \cdot 3$ & 3.91 & 0.031 & 68.9 & $10 \cdot 83$ & 0.046 \\
\hline & Urban & $18 \cdot 7$ & $3 \cdot 34$ & & $74 \cdot 2$ & 11.04 & \\
\hline \multirow{2}{*}{$11-14$ years } & Rural & 20.5 & 3.99 & 0.041 & $75 \cdot 9$ & $12 \cdot 22$ & 0.61 \\
\hline & Urban & $20 \cdot 2$ & $2 \cdot 88$ & & $74 \cdot 7$ & $11 \cdot 18$ & \\
\hline \multirow[t]{2}{*}{$\geq 15$ years } & Rural & $22 \cdot 0$ & 4.59 & 0.012 & $82 \cdot 4$ & $15 \cdot 33$ & 0.013 \\
\hline & Urban & $24 \cdot 1$ & 5.04 & & 87.4 & $14 \cdot 22$ & \\
\hline \multirow[t]{2}{*}{$\leq 10$ years } & Eat in front of TV & $18 \cdot 9$ & $3 \cdot 91$ & 0.72 & $69 \cdot 6$ & $10 \cdot 85$ & 0.46 \\
\hline & Do not eat in front of TV & $19 \cdot 3$ & $3 \cdot 34$ & & $70 \cdot 2$ & $10 \cdot 07$ & \\
\hline \multirow[t]{2}{*}{$11-14$ years } & Eat in front of TV & $19 \cdot 4$ & 3.99 & 0.050 & $75 \cdot 9$ & $12 \cdot 22$ & 0.041 \\
\hline & Do not eat in front of TV & $19 \cdot 1$ & $2 \cdot 88$ & & $72 \cdot 7$ & $11 \cdot 18$ & \\
\hline \multirow{2}{*}{$\geq 15$ years } & Eat in front of TV & $23 \cdot 2$ & 4.59 & 0.050 & $82 \cdot 4$ & $14 \cdot 31$ & 0.012 \\
\hline & Do not eat in front of TV & $22 \cdot 1$ & 5.04 & & $80 \cdot 3$ & $14 \cdot 22$ & \\
\hline
\end{tabular}

WC, waist circumference; TV, television.

${ }^{*}$ Values are significantly different between genders, living places and eating in front of the TV or not by the least significant difference test if $P<0.05$.

compared with those who did not eat while watching TV, except in the group of children aged $\leq 10$ years $(P=0 \cdot 46)$.

Table 5 shows that half of the parents knew the minimum water requirements for their children. However, about $80 \%$ of those parents did not know the best oil to be consumed. Among the 516 participants, only $39 \%$ of the parents know nutrients and food items that could contribute to obesity. Nearly $57 \%$ of them realized that salad is a healthy food choice and about $60 \%$ of mothers revealed that they mostly gave unhealthy options to their children when they are hungry as snacks. On the other hand, half of the mothers knew that fruits and vegetables are high in vitamins and minerals.

Table 6 shows that $40 \%$ of the mothers answered four or more questions correctly out of six, which indicates a sufficient level of nutritional knowledge, while $20 \%$ of the mothers were considered to have a moderate level of nutritional knowledge (three out of six questions answered correctly) and $40 \%$ had a low level of nutritional knowledge (fewer than three of the six questions answered correctly). We found a significantly decreased mean WC in the children and adolescents whose mothers had a moderate and high level of nutritional knowledge, compared with those whose mothers had a low level of nutritional knowledge.

\section{Discussion}

The purpose of the present study was to estimate the prevalence of overweight and obesity among children and adolescents in north Jordan and to explore the risk factors associated with such crucial phenomena. The major finding of the study was that overweight and obesity are serious health problems that may be common in all age groups including children and adolescents in both genders. The prevalence of overweight/obesity was $29.5 \%$, while about $11 \%$ of the study population was underweight. Our findings are similar to those of Mahajan et $a l .{ }^{(19)}$ in India, who found that the prevalence of childhood overweight and obesity ranged from 3 to $29 \%$ and indicated that the prevalence was higher in urban than 
in rural areas among children aged 6-12 years. A similar trend was also reported in Taiwan based on a crosssectional study conducted among schoolchildren. In that survey of 1366 school-aged Taiwanese children, it was found that the prevalence of obesity has steadily increased from 1980 to 1994 , from 12.4 to $16 \cdot 4 \%$ for boys and from $10 \cdot 1$ to $11 \cdot 1 \%$ for girls ${ }^{(20)}$

Underweight has also been reported among schoolchildren (6-11 years) and adolescents (12-18 years) in many Arab countries. Studies in Egypt, Lebanon, Tunisia, Jordan, Yemen and Arab Gulf countries showed that the prevalence of underweight ranged from 10 to $35 \%$ among schoolchildren and from 5 to $25 \%$ among adolescents. Despite the fact that most of these studies were not national baselines, they give a good indicator that a high percentage of underweight exists in these age groups in the region. Unhealthy dietary habits such as skipping breakfast, low intake of nutritious foods (such as milk,

Table 5 Parent's answers to the nutritional knowledge quiz ( $n 516$ ), Irbid, north Jordan, autumn 2016

\begin{tabular}{|c|c|c|c|}
\hline Question (correct answer) & $n$ & $\%$ & $P$ value* \\
\hline $\begin{array}{l}\text { Water requirements for children } \\
\qquad(\approx 6 \mathrm{cups} / \mathrm{d})\end{array}$ & & & 1.000 \\
\hline Correct & 258 & $50 \cdot 0$ & \\
\hline Incorrect & 258 & $50 \cdot 0$ & \\
\hline Best oil to be consumed (olive oil) & & & $<0.001$ \\
\hline Correct & 119 & $23 \cdot 1$ & \\
\hline Incorrect & 397 & $79 \cdot 6$ & \\
\hline $\begin{array}{l}\text { Nutrients and food items that could } \\
\text { contribute to obesity } \\
\text { (carbohydrates, rice, bread) }\end{array}$ & & & $<0.001$ \\
\hline Correct & 202 & 39.1 & \\
\hline Incorrect & 314 & 60.9 & \\
\hline Healthy food choices (salad) & & & 0.002 \\
\hline Correct & 223 & $43 \cdot 2$ & \\
\hline Incorrect & 293 & $56 \cdot 8$ & \\
\hline $\begin{array}{l}\text { Children preference when hungry } \\
\text { (homemade cooked meals) }\end{array}$ & & & $<0.001$ \\
\hline Correct & 207 & $40 \cdot 1$ & \\
\hline Incorrect & 309 & $59 \cdot 9$ & \\
\hline $\begin{array}{l}\text { High sources of vitamins and minerals } \\
\text { (vegetables and fruits) }\end{array}$ & & & 0.725 \\
\hline Correct & 254 & $49 \cdot 2$ & \\
\hline Incorrect & 262 & $50 \cdot 8$ & \\
\hline
\end{tabular}

*Values are significantly different between correct and incorrect answers by the least significant difference test if $P<0.05$. fruits and vegetables), high intake of 'empty-calorie' foods (such as soft drinks and some sweets) and lack of nutritional knowledge are the main factors for the high proportion of underweight among schoolchildren and adolescents in the majority of Arab countries ${ }^{(21)}$.

In the present study, a significant difference $(P<0.05)$ in BMI was found between boys and girls in the age groups $\leq 10$ years and 11-14 years, with higher BMI in males than females. This agrees with Jeffry and Voss ${ }^{(22)}$ who found in 2015 that parents of obese boys were not aware about the weight of their children; on the other hand, girls and their parents were under more cultural pressure about their perfect body shape. Our findings are also in agreement with Geer and Shen ${ }^{(23)}$ who found that male children have larger WC because they have more abdominal fat than female children, which distributed in an apple shape. However, our study findings revealed that females at age $\geq 15$ years had higher BMI than males of the same age. This could be due to hormonal changes, which are considered the main cause of weight changes at this age, and is in concordance with Waters et al. ${ }^{(24)}$, who found that women tend to crave foods high in fat and carbohydrate during specific phases of the menstrual cycle. Women also tend to have higher energy intake during their period and/or during premenstrual syndrome. Women with premenstrual syndrome suffer from any of a complex of symptoms including emotional tension and fluid retention in the days immediately before menstruation. Those symptoms change females' appetite and energy-rich food craving, which contributes to weight gain.

We also evaluated BMI in children and adolescents living in urban and rural settlements. Those living in a city had a higher BMI compared with those who lived in villages. Children who live in a village are known to be more active and tend to play more with their peers in the neighbourhood. Children also practise outdoor play and sports, which have been substituted by video games, TV, computers and mobile devices by children who live in a city, which makes urban children at higher risk of becoming overweight and obese $^{(12)}$. Furthermore, children who live in a village spend less time at school and walk to school, instead of using school buses or private cars, that makes them less obese than city children ${ }^{(25)}$. On the other hand, frequent walking

Table 6 Mean BMI and waist circumference of children and adolescents ( $n 516)$ by their mothers' level of nutritional knowledge, Irbid, north Jordan, autumn 2016

\begin{tabular}{|c|c|c|c|c|c|c|c|c|}
\hline \multirow[b]{2}{*}{ Level of nutritional knowledge } & \multirow[b]{2}{*}{$n$} & \multirow[b]{2}{*}{$\%$} & \multicolumn{3}{|c|}{ BMI $\left(\mathrm{kg} / \mathrm{m}^{2}\right)$} & \multicolumn{3}{|c|}{ WC (cm) } \\
\hline & & & Mean & SD & $P$ value & Mean & SD & $P$ value \\
\hline High & 207 & 40 & 19.5 & $3 \cdot 61$ & 0.076 & $74 \cdot 2^{a}$ & $10 \cdot 42$ & 0.045 \\
\hline Moderate & 103 & 20 & $19 \cdot 8$ & $3 \cdot 24$ & & $74 \cdot 7^{\mathrm{a}}$ & $11 \cdot 15$ & \\
\hline Low & 206 & 40 & $20 \cdot 7$ & $4 \cdot 25$ & & $77.9^{b}$ & $12 \cdot 21$ & \\
\hline
\end{tabular}

WC, waist circumference.

${ }_{\mathrm{a}, \mathrm{b}}$ Mean values within a column with unlike superscript letters were significantly different by the least significant difference test $(P<0.05)$. 
or cycling to school makes city children more active than those children who are living in villages and less likely to be overweight/obese ${ }^{(26)}$.

The $\mathrm{WHO}^{(27)}$ reported that several environmental factors, including low air quality, pollution and high-density traffic, lack of parks and sidewalks, violence and absence of recreational facilities due to increased urbanization, might discourage participation in physical activity in both adults and children, thus increasing the rate of overweight and obesity ${ }^{(28)}$.

Our results confirmed that children older than 11 years who eat in front of the TV tend to have higher BMI and higher WC. These findings agree with a study conducted on 523 children who ate in front of the TV, which found that $49 \%$ of these children were obese ${ }^{(29)}$. Commercials and mass media have a significant effect on eating habits. The amount of time spent in front of the TV and the content watched can be a reason for developing obesity. TV not only contributes to physical inactivity, but also commercials and other programmes encourage viewers to eat more ${ }^{(1)}$. In addition, watching TV goes hand in hand with eating snacks, most of which contain a large amount of energy. In the current study, among children aged $\leq 10$ years, those who ate in front of the TV did not have a significantly different BMI or WC compared with those who did not tend to eat while watching TV. This is likely explained because most hormonal changes occur at about 15 years of age, which may make the older group more susceptible to obesity than younger children ${ }^{(30)}$. Also, younger children tend to be more physically active and interested in playing more than older children and adolescents.

Parental nutritional knowledge level was generally low in the present study, as most of the mothers $(60 \%)$ did not answer an adequate number of questions correctly. Also, children of mothers having a high/moderate level of knowledge tended to have a decreased WC compared with children of mothers having a low level of nutritional knowledge. This may indicate that mothers or parents may pass on wrong behaviours and information to their children, which may affect their choices and dietary practices later in life and in turn affect their weight and health in adulthood.

\section{Conclusion}

The current study revealed that obesity is a growing health problem in child and adolescent school students in Irbid city, which requires an appropriate intervention, especially considering the alarming rates of obesity and its associated co-morbidities among Jordanian schoolchildren. Public health efforts in Jordan should be directed towards the creation of new prevention programmes at the individual, family and community level to promote schoolchildren's health.
More research is required on the behavioural and biological causes of overweight and obesity, and on the prevalence among different regions, ages and settings. Appropriate health policies are urgently needed to prevent or reduce the obesity problem. Parents should learn more about proper nutrition and should be advised to monitor the dietary habits of their children and to correct any unhealthy habits as early as possible. Moreover, parents should play an important role in motivating their children to practise different sports in- and outside home. It is recommended that schoolteachers must be engaged in healthy nutrition training workshops to emphasize the importance of balanced nutrition for all school students in the north of Jordan.

\section{Acknowledgements}

Acknowledgements: The authors wish to thank the public and private schools of Irbid District for their help in conducting this research. Financial support: The work was supported by the Deanship of Research of Jordan University of Science and Technology (grant number 195/ 2016). The funder had no role in the design, analysis or writing of this article. Conflict of interest: There is no conflict of interest for any author regarding this manuscript. Authorship: H.S.S. conceived of and designed the study, conducted the analysis and interpretation of the data, and wrote the manuscript. Y.A.-S. conducted the research, collected the data and helped in drafting the manuscript. H.B. helped in drafting the manuscript. N.A.-B. carried out critical revision of the manuscript. Ethics of buman subject participation: This study was conducted according to the guidelines laid down in the Declaration of Helsinki and all procedures involving human subjects were approved by the Institutional Review Boards of the Medical School of Jordan University of Science and Technology and King Abdullah University Hospital, Irbid. Written informed consent was obtained from all subjects.

\section{References}

1. Musaiger AO (2004) Overweight and obesity in Eastern Mediterranean Region: can we control it? East Mediterr Health J 10, 789-793.

2. Patterson R, Risby A \& Chan MY (2012) Consumption of takeaway and fast food in a deprived inner London borough: are they associated with childhood obesity? BMJ Open 2, $\mathrm{e} 000402$.

3. Dehghan M, Akhtar-Danesh N \& Merchant AT (2005) Childhood obesity, prevalence and prevention. Nutr J4, 24.

4. World Health Organization (2000) Obesity: Preventing and Managing the Global Epidemic. Report of a WHO Consultation. WHO Technical Report Series no. 894. Geneva: WHO.

5. Keding GB, Msuya JM, Maass BL et al. (2013) Obesity as a public health problem among adult women in rural Tanzania. Glob J Health Sci 1, 359-371. 
6. Gupta N, Goel K, Shah P et al. (2012) Childhood obesity in developing countries: epidemiology, determinants, and prevention. Endocr Rev 33, 48-70.

7. De Onis M, Blössner M \& Borghi E (2010) Global prevalence and trends of overweight and obesity among preschool children. Am J Clin Nutr 92, 1257-1264.

8. Abdul-Rasoul M (2012) Obesity in children and adolescents in Gulf countries: facts and solutions. Avances en Diabetología 28, 64-69.

9. Singh M \& Sharma M (2005) Risk factors for obesity in children. Indian Pediatr 42, 183-185.

10. Mosha T \& Fungo S (2010) Prevalence of overweight and obesity among children aged 6-12 years in Dodoma and Kinondoni Municipalities, Tanzania. Tanzan J Health Res 12, 6-16.

11. Wang Y \& Lobstein T (2006) Worldwide trends in childhood overweight and obesity. Int J Pediar Obes 1, 11-25.

12. Kelishadi R (2007) Childhood overweight, obesity, and the metabolic syndrome in developing countries. Epidemiol Rev 29, 62-76.

13. World Health Organization Consultation on Obesity (1997) Preventing and Managing the Global Epidemic: Report of a WHO Consultation on Obesity, Geneva, Switzerland, 3-5 June 1997. Geneva: WHO.

14. World Health Organization (2005) The challenge of obesity in the WHO European Region. Fact sheet no. EURO/13/05. http://www.euro.who.int/_data/assets/pdf_file/0018/1023 84/fs1305e.pdf (accessed May 2018).

15. World Health Organization (2009) European Environment and Health Information System. Prevalence of overweight and obesity in children and adolescents. Fact sheet no. 2.3. http://www.euro.who.int/_data/assets/pdf_file/0005/96980/ 2.3.-Prevalence-of-overweight-and-obesity-EDITED_layouted_ V3.pdf?ua=1 (accessed May 2018).

16. James P (2004) Obesity: the worldwide epidemic. Clin Dermatol 23, 276-280.

17. Cole TJ, Flegal KM, Nicholls D et al. (2007) Body mass index cut offs to define thinness in children and adolescents: international survey. BMJ 335, 194.
18. Addo O \& Himes J (1998) Reference curves for triceps and subscapular skinfold thicknesses in US children and adolescents. Am J Clin Nutr 91, 635-642.

19. Mahajan P, Purty A, Singh Z et al. (2011) Study of childhood obesity among school children aged 6 to 12 years in Union Territory of Puducherry. Indian J Community Med 36, 45-50.

20. Chu NF (2001) Prevalence and trends of obesity among school children in Taiwan - the Taipei Children Heart Study. Int J Obes Relat Metab Disord 25, 170-176.

21. Musaiger AO (2011) Overweight and obesity in Eastern Mediterranean region: prevalence and possible causes. J Obes 2011, 407237.

22. Jeffry AN \& Voss LD (2004) Parents' awareness of overweight in themselves and their children: cross sectional study within a cohort (Early Bird 21). BMJ 330, 23.

23. Geer EB \& Shen W (2009) Gender differences in insulin resistance, body composition and energy balance. Gend Med 6, 60-75.

24. Waters E, de Silva Sanigorski A, Hall B et al. (2011) Interventions for preventing obesity in children. Cochrane Database Syst Rev issue 12, CD001871.

25. Itoi A, Yamada Y, Watanabe Y et al. (2012) Physical activity, energy intake, and obesity prevalence among urban and rural schoolchildren aged 11-12 years in Japan. Appl Physiol Nutr Metab 37, 1189-1199.

26. Van Sluijs EM, Fearne VA, Mattocks C et al. (2009) The contribution of active travel to children's physical activity levels: cross-sectional results from the ALSPAC study. Prev Med 48, 519-524.

27. World Health Organization (2008) Physical Inactivity: A Global Public Health Problem. Geneva: WHO.

28. Birch L \& Fisher J (2010) Development of eating behaviors among children and adolescents. Pediatr 101, Suppl. 2, 539-549.

29. Larson N \& Story M (2013) A review of snacking patterns among children and adolescents: what are the implications of snacking for weight status? Child Obes 9, 104-115.

30. Cadogan J, Blumsohn A, Barker ME et al. (1998) A longitudinal study of bone gain in pubertal girls: anthropometric and biochemical correlates. J Bone Miner Res 13, 1602-1612. 